\title{
Correction to: Hypovitaminosis D in migrant children in Switzerland: a retrospective study
}

\author{
Olivia Fahrni ${ }^{1}\left[\right.$ [ $\cdot$ Alexandra Wilhelm-Bals ${ }^{2}$ [D $\cdot$ Klara M. Posfay-Barbe $^{3}$ (D) Noémie Wagner $^{3}$
}

Published online: 6 August 2021

(c) Springer-Verlag GmbH Germany, part of Springer Nature 2021

Correction to: European Journal of Pediatrics

https://doi.org/10.1007/s00431-021-04143-7

In the original published version of the above article, the authors wanted to update Table 1 footnote as follows:

Regions are emphasised in bold. Subcategories of severe $(25(\mathrm{OH}) \mathrm{D}<25 \mathrm{nmol} / \mathrm{L})$ and mild $(25(\mathrm{OH}) \mathrm{D} 25-50 \mathrm{nmol} / \mathrm{L})$ vitamin $\mathrm{D}$ deficiencies are emphasised in italic.

The original article has been corrected.

Publisher's Note Springer Nature remains neutral with regard to jurisdictional claims in published maps and institutional affiliations.

The original article can be found online at https://doi.org/10.1007/ s00431-021-04143-7.

Olivia Fahrni

Olivia.Fahrni@gmail.com

Alexandra Wilhelm-Bals

Alexandra.Wilhelm-bals@hcuge.ch

Klara M. Posfay-Barbe

Klara.Posfaybarbe@hcuge.ch

Noémie Wagner

Noemie.Wagner@hcuge.ch

1 Faculty of Medicine, University of Geneva, Geneva,

Switzerland

2 Pediatric Nephrology Unit, Geneva University Hospitals and Faculty of Medicine, Geneva, Switzerland

3 Pediatric Infectious Diseases Unit, Geneva University Hospitals and Faculty of Medicine, Geneva, Switzerland 